\title{
Reliability of Reinforced Concrete Structures Subjected to Corrosion-Fatigue and Climate Change
}

\author{
Emilio Bastidas-Arteaga*
}

(Received November 26, 2016, Accepted January 7, 2018)

\begin{abstract}
Durability of reinforced concrete (RC) structures is affected by certain environmental conditions and operational actions which can reduce their lifetime significantly. Among these actions, this paper proposes a stochastic model that accounts for the combined effects of chloride-induced corrosion, climate change and cyclic loading. Separately, corrosion leads to cross-section reduction, climate change produces changes in temperature and humidity and fatigue induces nucleation and propagation of cracks in the rebars. When considered together, pitting corrosion nucleates cracks while environmental factors affect the kinematics of chloride ingress and corrosion propagation. The proposed approach is illustrated with the reliability analysis of a bridge girder subjected to cyclic loading under various environmental conditions. The overall results indicate that climate change effect induces lifetime reductions ranging between 1.4 and $2.3 \%$ if fatigue load is neglected. Under cyclic loading, total lifetime reduction increases up to $7 \%$.
\end{abstract}

Keywords: reliability, corrosion-fatigue, reinforced concrete, climate change, chloride ingress.

\section{Introduction}

Reinforced concrete (RC) civil infrastructure systems are critical assets for the socioeconomic development of any country. Designing and maintaining these systems for a particular service lifetime have been recognized as critical issues worldwide. RC structures are characterized by high durability; however, during their operational life, they are subjected to internal and external actions that affect performance, serviceability and safety (Imam et al. 2015; Kim et al. 2016; Marquez-Peñaranda et al. 2016; Morga and Marano 2015; Sánchez-Silva and Klutke 2016). Nowadays, many deteriorated structures are evaluated for possible repair and continued service because their replacement would be economically unfeasible. For example, about 173,000 bridges in the United States are structurally deficient or functionally obsolete due in part to corrosion (Bhide 1999; Pritzl et al. 2014; Radlińska et al. 2014). Regarding costs, Koch et al. (2016) reported that the global cost of corrosion is US\$2.5 trillion (about 3.4\% of the global Gross Domestic Product). Thus, developing robust models for prediction and strategies for periodic inspection and maintenance plays a significant role in enabling target reliabilities to be met over

UBL, Université de Nantes, GeM, Institute for Research in Civil and Mechanical Engineering/Sea and Littoral Research Institute, CNRS UMR 6183/FR 3473, 2 rue de la Houssinière, BP 99208, 44322 Nantes Cedex 3, France. *Corresponding Author;

E-mail: emilio.bastidas@univ-nantes.fr Copyright (c) The Author(s) 2018. This article is an open access publication a period of continued service (Bastidas-Arteaga et al. 2009; Bastidas-Arteaga and Schoefs 2015; Clifton 1993; Mori and Ellingwood 1995).

This paper focuses on a combined corrosion-fatigue deterioration mechanism. Corrosion is induced by chloride penetration that results in turn from a complex interaction between physical and chemical processes that are driven by environmental surrounding conditions (Bastidas-Arteaga and Stewart 2016; Nguyen et al. 2017; Saetta et al. 1993). Combined corrosion-fatigue deterioration results from the action of cycling stresses in corrosive environments. Localized corrosion leading to pitting may provide sites for fatigue crack initiation. For example, several experimental studies have shown that pitting corrosion has been responsible for the nucleation of fatigue cracks in a wide range of steels and aluminum alloys (Ahn et al. 1992; Chen and Duquette 1992; Kondo 1989). Corrosive agents (e.g., seawater) increase the fatigue crack growth rate (Gangloff 2005), whereas the morphology of metals/alloys at micro-level governs the pit nucleation sites (Rajasankar and Iyer 2006).

There exists a limited amount of experimental tests on corrosion-fatigue in RC structures. Ahn and Reddy (2001) performed an experimental study to evaluate the durability of RC beams subjected to fatigue loading and chloride ingress. The tests included 16 beams and accounted for the influence of static and cyclic loading for different water/ cement ratios. Alternate filling and draining of a tank simulated the marine tidal zone, and a galvanostatic corrosion technique was used to accelerate corrosion of the reinforcement. The ultimate strength of the beams was tested after 78,000 cycles by applying four-point flexural loading. The results indicated that beams subjected to cyclic loading 
during the exposure period showed lower ultimate strength than those subjected to static loading. Taking into account the imminent reduction of ultimate strength, other experimental studies focused on estimating the effectiveness of using composite repair materials (Al-Hammoud et al. 2011; ElSafty et al. 2014; Masoud et al. 2005; Song and Yu 2015). More recently, Wang et al. (2018) performed a comprehensive experimental study to quantify the effects of cyclic load on the chloride ingress process. They found that considering fatigue loading conditions have important effects in lifetime assessment depending on the aggressiveness of the surrounding environment.

Modeling the combined effect of corrosion and fatigue remains still an open challenge. Bastidas-Arteaga et al. (2009) proposed a first probabilistic corrosion-fatigue model for RC structures subjected to chloride ingress; however, this model uses a simplified solution of Fick's law to simulate the chloride ingress process that does not always represent reality. On the other hand, experimental evidence indicates that the chloride ingress is highly influenced by the weather conditions at the surrounding environment-i.e. temperature and humidity. Since climate change studies predict several changes in the climate (IPCC 2013), the impact of global warming on chloride ingress, and therefore on structural reliability, should be also considered in the assessment of the structural behavior.

Within this context, the main goal of this paper is to improve the model proposed by Bastidas-Arteaga et al. (2009) to be able to consider the influence of realistic exposure conditions (including climate change) on failure probability. To accomplish this objective, the proposed lifetime prediction approach includes a numerical solution for the transport governing equations in the assessment of the corrosion initiation time.

The paper starts describing the deterioration model used to combine the interaction between corrosion and fatigue (Sect. 2). Section 3 presents a stochastic weather model, including global warming. Section 4 describes the stochastic approach to the problem, and Sect. 5 applies the proposed methodology to the reliability assessment of a bridge girder subjected to various environmental and cyclic loading conditions.

\section{Deterioration Model}

Assessment of corrosion-fatigue effects on RC structures is a difficult task because several deterioration mechanisms interact in the process. The corrosion-fatigue deterioration process accounts for the interaction between three mechanisms: (i) chloride ingress, (ii) concrete cracking due to corrosion propagation and (iii) cyclic loading (Fig. 1). Chloride ingress induces both corrosion initiation and pitting corrosion leading to crack nucleation on the steel bar. The accumulation of corrosion products in the steel/concrete interface generates concrete cracking, which plays an important role in the steel corrosion rate when excessive concrete cracking is reached. Cyclic loading takes part in the process during the stages of pit-to-crack transition and crack growth. Based on the previous considerations, the corrosionfatigue process is divided into three stages: (i) corrosion initiation and pit nucleation, $t_{c p}$; (ii) pit-to-crack transition, $t_{p t}$; and (iii) crack growth, $t_{c g}$.

The proposed deterioration model does not account for the loss of adhesion at the steel/concrete interface caused by corrosion propagation as well as the effect of permanent charges on the long-term mechanical behavior. Further model developments will be necessary in the future to integrate these aspects and improve lifetime assessment.

\subsection{Corrosion Initiation and Pit Nucleation}

This stage is divided into two sub-stages: (i) time to corrosion initiation, $t_{c i n i}$, and (ii) time to pit nucleation, $t_{p n}$. The first sub-stage encompasses the time from the end of construction until corrosion begins. For the assessment of $t_{\text {cini }}$, this section presents a formulation for chloride ingress modeling that considers the interaction between three physical problems: chloride ingress, moisture diffusion and heat transfer. Each phenomenon is represented by a partial differential equation (PDE) expressed in the following general form (Bastidas-Arteaga et al. 2011):

$$
\zeta \frac{\partial \psi}{\partial t}=\underbrace{\operatorname{div} J}_{\text {diffusion }}+\underbrace{\operatorname{div} J^{\prime}}_{\text {convection }}
$$

where $\psi$ represents the studied parameter (chloride concentration, relative humidity content or temperature), $t$ is the time period and the correspondence between $\zeta, J, J^{\prime}$ and the terms for the physical problem is presented in Table 1 .

For chloride ingress, $C_{f c}$ is the concentration of free chlorides, $h$ is the relative humidity and $D_{c}^{*}$ and $D_{h}^{*}$ represent the apparent chloride and humidity diffusion coefficients, respectively:

$$
\begin{aligned}
& D_{c}^{*}=\frac{D_{c, r e f} f_{1}(T) f_{2}(t) f_{3}(h)}{1+\left(1 / w_{e}\right)\left(\partial C_{b c} / \partial C_{f c}\right)} \\
& D_{h}^{*}=\frac{D_{h, r e f} g_{1}(h) g_{2}(T) g_{3}\left(t_{e}\right)}{1+\left(1 / w_{e}\right)\left(\partial C_{b c} / \partial C_{f c}\right)}
\end{aligned}
$$

where $D_{c, r e f}$ and $D_{h, r e f}$ are reference diffusion coefficients measured to standard conditions (Saetta et al. 1993), $w_{e}$ is the evaporable water content, and $f_{i}$ and $g_{i}$ are correction functions to account for the effects of temperature $(T)$, relative humidity, ageing and degree of hydration of concrete. These functions are detailed in (Bastidas-Arteaga et al. 2011). The term $\partial C_{b c} / \partial C_{f c}$ represents the binding capacity of the cementitious system which relates the free and bound chlorides concentration at equilibrium. $C_{b c}$ is the concentration of bound chlorides, and $w_{e}$, and the pore relative humidity.

For moisture diffusion, the humidity diffusion coefficient $D_{h}$ is estimated by accounting for the influence of the parameters presented in Eq. (3). The term $\partial w_{e} / \partial h$ (Table 1) represents the moisture capacity which relates $h$ and $w_{e}$. For a given temperature this relationship has been determined 


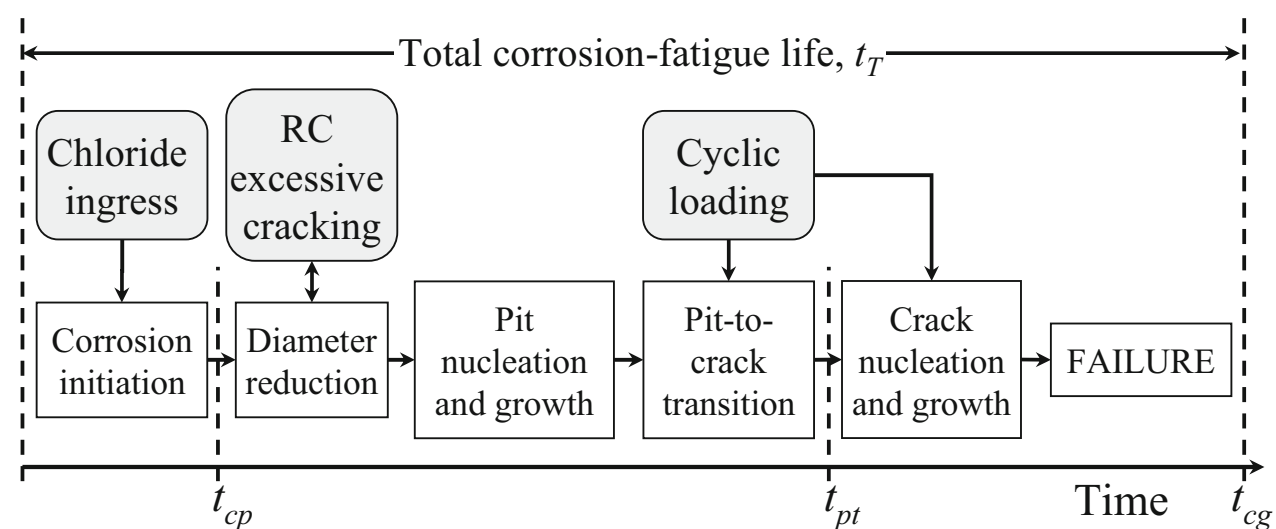

Fig. 1 Description of the corrosion-fatigue deterioration process in RC structures.

Table 1 Correspondence between Eq. (1) and the governing differential equations.

\begin{tabular}{c|c|c|c|c|c}
\hline Physical problem & $\psi$ & $\zeta$ & $J$ & $J^{\prime}$ & $q_{\psi}^{s}$ \\
\hline \hline Chloride ingress & $C_{f c}$ & 1 & $D_{c}^{*} \vec{\nabla} C_{f c}$ & $C_{f c} D_{h}^{*} \vec{\nabla} h$ & $q_{h}^{s}$ \\
\hline Moisture diffusion & $h$ & $\partial w_{e} / \partial h$ & $D_{h}^{*} \vec{\nabla} h$ & 0 & 0 \\
\hline Heat transfer & $T$ & $\rho_{c} c_{q}$ & $\lambda \vec{\nabla} T$ & 0 & 0 \\
\hline
\end{tabular}

experimentally by adsorption isotherms. According to the Brunauer-Skalny-Bodor (BSB) model (Brunauer et al. 1969) and the empirical expressions of $\mathrm{Xi}$ et al. (1994), the adsorption isotherm depends on temperature, water/cement ratio, $w / c$, and the equivalent hydration (curing) period, $t_{e}$. This work adopts the BSB model to represent the moisture capacity.

Finally, for heat transfer (Table 1), $\rho_{c}$ is the density of the concrete, $c_{q}$ is the concrete specific heat capacity, $\lambda$ is the thermal conductivity of concrete and $T$ is the temperature inside the concrete matrix after time $t$.

The boundary conditions at the exposed surfaces consider the flux of $\psi$ crossing the concrete surface, (Robin boundary condition) (Saetta et al. 1993):

$$
q_{\psi}^{s}=\underbrace{B_{\psi}\left(\psi^{s}-\psi_{\text {env }}\right)}_{\text {diffusion }}+\underbrace{\psi_{\text {env }} q_{\psi}^{s^{\prime}}}_{\text {convection }}
$$

where $B_{\psi}$ is the surface transfer coefficient, $\psi^{s}$ is the value of $\psi$ at the exposed surface and $\psi_{\text {env }}$ represents the value of $\psi$ in the surrounding environment for each physical problem. The terms in Eq. (4) are also presented in Table 1. By fitting experimental data, Saetta et al. (1993) reported that the chloride surface transfer coefficient, $B C_{f_{c}}$, varies between $1 \mathrm{~m} / \mathrm{s}$ and $6 \mathrm{~m} / \mathrm{s}$. Typical values of the humidity surface transfer coefficient, $B_{h}$, are in the range of $2.43 \times 10^{-7} \mathrm{~m} / \mathrm{s}$ and $4.17 \times 10^{-7} \mathrm{~m} / \mathrm{s}$ (Akita et al. 1997). Finally, Khan et al. (1998) observed that the temperature surface transfer coefficient, $B_{T}$, fluctuates between $6.2 \mathrm{~W} /\left(\mathrm{m}^{2}{ }^{\circ} \mathrm{C}\right)$ and $9.3 \mathrm{~W} /$ $\left(\mathrm{m}^{2}{ }^{\circ} \mathrm{C}\right)$.

The flow of chlorides into concrete is estimated by solving simultaneously the system of equations described by Eq. (1) and Table 1. The numerical approach used to solve the coupled system of PDEs combines a finite element formulation with finite difference to estimate the spatial and temporal variation of $C_{f c}, h$ and $T$. Then, the time to corrosion initiation, $t_{c i n i}$, is estimated by comparing the chloride concentration at the cover depth, $c_{t}$, with a threshold concentration for corrosion initiation $C_{t h}$.

From a comparison between the times-spans of the time to corrosion initiation and the time to pit nucleation, BastidasArteaga et al. (2009) found that the length of $t_{p n}$ can be neglected.

\subsection{Pit-to-Crack Transition}

The time of transition from pit to crack is defined as the time at which the maximum pit depth reaches a critical value leading to crack nucleation. Crack nucleation depends on the competition between the processes of pit and crack growth. The rate competition criterion, where the transition takes part when the crack growth rate, $d a / d t$, exceeds the pit growth rate, $d p / d t$ (Fig. 2), is taken into consideration to estimate the length of this stage (Chen et al. 1996; Kondo 1989). For this criterion, $d p / d t$ is described by electrochemical mechanisms

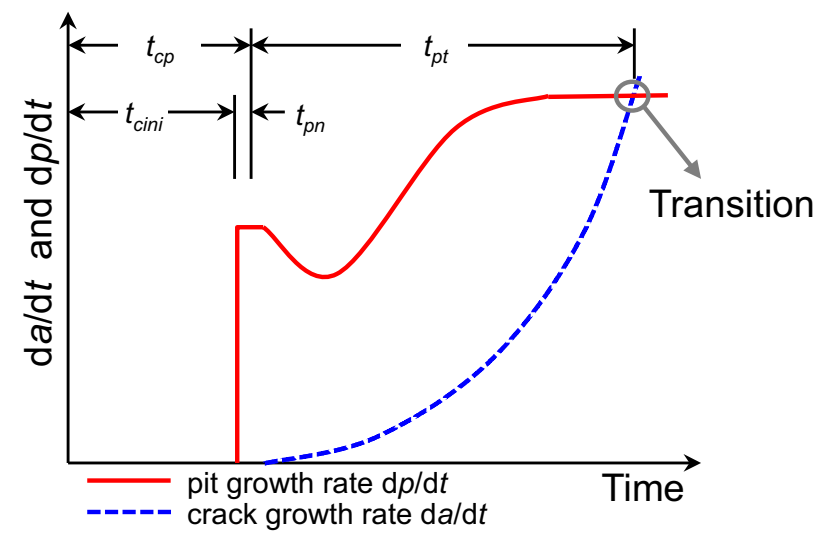

Fig. 2 Rate completion criterion for estimating the pit-tocrack transition time. 
and $d a / d t$ is estimated in terms of linear elastic fracture mechanics.

After pit nucleation, pit growth can be estimated in terms of a change in the volumetric rate by using Faraday's law (Jones 1992):

$$
p(t)=0.0116 \alpha \int i_{\text {corr }}(t) d t
$$

where $p(t)$ is the pit depth (in mm) at time $t, \alpha$ is the ratio between pitting and uniform corrosion depths, and $i_{\text {corr }}(t)$ is the time-variant corrosion rate $\left(\mu \mathrm{A} / \mathrm{cm}^{2}\right)$. Given the complexity of the corrosion process in $\mathrm{RC}, i_{\text {corr }}$ depends on many factors such as concrete $\mathrm{pH}$, oxygen, water and chlorides availability. Bastidas-Arteaga et al. (2007) proposed a time-variant corrosion rate function, $i_{\text {corr }}(t)$, which takes into account these factors as environmental aggressiveness:

$$
i_{c o r r}(t)=\frac{m_{\text {ini }}(t) i_{\text {ini }}(t)+m_{a c}(t) i_{t h}}{m_{\text {ini }}(t)+m_{a c}(t)}
$$

where $m_{\text {ini }}(t)$ and $m_{a c}(t)$ are membership functions for the initial and the active corrosion ages, respectively, $i_{\text {ini }}(t)$ is an initial corrosion rate function ( $\mathrm{Vu}$ and Stewart 2000) and $i_{\text {th }}$ is a threshold corrosion rate. The value of $i_{t h}$ depends mainly on environmental aggressiveness which can be expressed as a function of the availability of water, oxygen and chloride concentration at the corrosion cell. Environmental aggressiveness takes an active role in the corrosion rate after severe cracking of concrete. Thus, with the previous considerations, the effect of concrete cracking also is considered in the model. By assuming that the pit shape has a spherical shape the pit growth rate can be obtained by deriving Eq. (5) with respect to time:

$$
\frac{d p}{d t}=0.0116 \alpha i_{c o r r}(t)
$$

On the other hand, the fatigue crack growth rate is estimated by using Paris-Erdogan law (Bastidas-Arteaga et al. 2009):

$$
\frac{d a}{d N}=C_{p}(\Delta K)^{m}
$$

where $a$ is the crack size, $N$ is the number of cycles, $\Delta K$ is the alternating stress intensity factor, and $C_{p}$ and $m$ are material constants. Salah el Din and Lovegrove (1982), reported experimental values for $C_{p}$ and $m$ corresponding to medium and long crack growth stages for reinforcing bars:

$$
\frac{d a}{d N}=\left\{\begin{array}{cc}
3.83 \times 10^{-29}(\Delta K)^{20.863} & \text { for } \Delta K \leq 9 M P a \sqrt{m} \\
3.16 \times 10^{-12}(\Delta K)^{3.143} & \text { otherwise }
\end{array}\right.
$$

where $\Delta K$ is the stress intensity factor for the cracked bar which can be estimated as:

$$
\Delta K(a)=\Delta \sigma Y\left(a / d_{0}\right) \sqrt{\pi a}
$$

where $\Delta \sigma$ is the stress range, i.e. $\Delta \sigma=\sigma_{\max }-\sigma_{\min }, d_{0}$ is the initial diameter of the bar and $Y\left(a / d_{0}\right)$ is a dimensionless geometry notched specimen function (Murakami and Nisi$\operatorname{tani} 1975)$.

To find the time for pit-to-crack transition, $t_{p t}$, an equivalent stress intensity factor for the pit, $\Delta K_{p i t}$ must be estimated. $\Delta K_{\text {pit }}$ is found by substituting $a$ in Eq. (10) by the pit depth $p(t)$ (Eq. (5)):

$$
\Delta K_{p i t}(p(t))=\Delta \sigma Y\left(p(t) / d_{0}\right) \sqrt{\pi p(t)}
$$

Then, the equivalent crack growth rate becomes:

$$
\frac{d a}{d t}=C_{p}\left(\Delta K_{p i t}(t)\right)^{m} f
$$

where $f$ is the frequency of the cyclic load. Therefore, the time of pit-to-crack transition is numerically obtained by equating the pit growth rate (Eq. 7) with the equivalent crack growth rate (Eq. 12), and solving for $t_{p t}$ in:

$$
0.0116 \alpha i_{c o r r}\left(t_{p t}\right)=C_{p}\left(\Delta K_{p i t}\left(t_{p t}\right)\right)^{m} f
$$

It is important to mention that the crack growth process does not account for effects of temperature and relative humidity. Further research is required to improve the modeling of crack propagation in rebars under realistic environmental conditions.

\subsection{Crack Growth}

Crack growth modeling is concerned with the time from the crack initiation until the crack size reaches a value inducing failure of the cross-section. The initial crack size, $a_{0}$, is estimated as the pit depth at time for pit-to-crack transition, i.e. $a_{0}=p\left(t_{p t}\right)$ Eq. (5). The size of the critical crack, $a_{c}$, is defined as the crack size at which the RC member reaches a limit state of resistance (e.g. bending capacity). This time is obtained by integrating Eq. (9):

$$
t_{c g}=\left\{\begin{array}{cc}
\frac{1}{f}\left(\int_{a_{0}}^{a_{1}} \frac{d a}{3.83 \times 10^{-29}(\Delta K)^{20.863}}+\int_{a_{1}}^{a_{c}} \frac{d a}{3.16 \times 10^{-12}(\Delta K)^{3.143}}\right) & \text { for } a_{0}<a_{1} \\
\frac{1}{f} \int_{a_{0}}^{a_{c}} \frac{d a}{3.16 \times 10^{-12}(\Delta K)^{3.143}} & \text { otherwise }
\end{array}\right.
$$

where $a_{1}$ is the crack size at which the crack growth rate changes from medium to long crack growth; this transition occurs when the crack size reaches a threshold value,- - i.e. $\Delta K\left(a_{1}\right)=9 \mathrm{MPa} \sqrt{\mathrm{m}}$ (Salah el Din and Lovegrove 1982). This model is a convenient tool to evaluate the total structural lifetime. Its robustness lies in the implicit integration of various parameters and processes affecting the RC lifetime, which is very convenient for reliability analysis. 


\section{Modeling Weather Including Climate Change Effects}

\subsection{Basic Considerations and Model Description}

Until recently all corrosion-related research assumed constant average climatic conditions for the development of deterioration models. However, it is expected a temperature rise up to $2{ }^{\circ} \mathrm{C}$ by 2100 even under an optimistic scenario where $\mathrm{CO}_{2}$ emissions are abated (IPCC 2013). Rises in temperature increase the rate of infiltration of deleterious substances (increased material diffusivity) and increase the corrosion rate of steel. Optimum relative humidity levels may also increase the rate of infiltration of deleterious substances (Stewart et al. 2011).

Given that chloride penetration and corrosion kinetics are governed by surrounding humidity and temperature-i.e., Equation (2), it is necessary to implement a comprehensive model of weather (humidity and temperature). The basic science of weather modeling, including the greenhouse effect, is well understood and has been widely discussed. Nevertheless, given the difficulties of integrating a fully coupled model of weather with the deterioration model, a simplified model of weather is presented in this section. It accounts for the following aspects:

- influence of global warming,

- seasonal variation of weather parameters, and

- random nature of weather.

Climate change effect is modeled by assuming a linear variation of the weather parameters (humidity or temperature); while seasonal variations of humidity or temperature follow a sinusoidal shape. The uncertainties related to weather are treated in the following section.

The change of temperature and humidity produced by global warming for the upcoming years is modeled by a linear time-variant function. By denoting $\phi$ as the weather parameter (humidity or temperature), the annual mean value of $\phi$ for a period of analysis $t_{a}$ (i.e., $t_{a}=100$ years):

$$
\bar{\phi}(t)=\phi_{0}+\left(\phi_{t_{a}}-\phi_{0}\right) t / t_{a}
$$

where $\phi_{0}$ and $\phi_{t_{a}}$ are the values of the annual means of humidity or temperature at the beginning of the analysis $(t=0$ year $)$ and at the end of the reference period $\left(t=t_{a}\right.$ year), respectively. To take seasonal variations of humidity and temperature into consideration, the model divides the year into two seasons hot and cold for temperature, and wet and dry for humidity. Actual forecasts of global warming also indicate that the droughts increase the length of hot (or wet) seasons, $L_{h}$, with respect to the length of cold (or dry) seasons, $L_{c}$ (IPCC 2013). By defining $R_{0}$ as the normalized duration of the cold (or dry) season for $t=0$, i.e. $R_{0}=L_{c}$ l ( 1 year), and $R_{t_{a}}$ as the normalized duration of the cold or dry season for $t=t_{a}$ ( $L_{c}$ in years); it is possible to linearly estimate the normalized duration of the cold or dry season $R$ for a given $t$ :

$$
R(t)=R_{0}+\left(R_{t_{a}}-R_{0}\right)\lfloor t\rfloor / t_{a}
$$

where $\lfloor t\rfloor$ represents the floor function that gives as output the greatest integer that is less than or equal to $t$. Thus by using a sinusoidal formulation to simulate the seasonal variation of $\phi$ around the linear trend (Eq. 15), the seasonal mean of $\phi$ for hot or wet seasons is:

$$
\bar{\kappa}(t)=\bar{\phi}(t)+\frac{\phi_{\max }-\phi_{\min }}{2} \sin \left(\frac{t-\lfloor t\rfloor}{1-R(t)} \pi\right)
$$

and for cold or dry seasons

$$
\bar{\kappa}(t)=\bar{\phi}(t)-\frac{\phi_{\text {max }}-\phi_{\min }}{2} \sin \left(\frac{t-\lfloor t\rfloor}{1-R(t)} \pi\right)
$$

where $\phi_{\max }$ and $\phi_{\min }$ are respectively the maximum and minimum values taken by $\phi$ during 1 year and $t$ is expressed in years.

\subsection{Selected Scenarios}

The IPCC Fifth Assessment Report (AR5) (IPCC 2013) uses Representative Concentration Pathways (RCPs) where RCP 8.5, RCP 6.0 and RCP 4.5 are roughly equivalent to $\mathrm{A} 1 \mathrm{FI}$ or $\mathrm{A} 2, \mathrm{~A} 1 \mathrm{~B}$, and $\mathrm{A} 1 \mathrm{~B}$ to $\mathrm{B} 1$ emission scenarios, respectively (Inman 2011). These RCPs were considered to be representative of the literature, and included a mitigation scenario leading to a low forcing level (RCP 2.6), two medium stabilization scenarios (RCP 4.5/RCP 6) and one high baseline emission scenarios (RCP 8.5) (Moss et al. 2010).

There are important uncertainties related to the consequences of climate change that come mainly from the lack of knowledge about the policies of the society and the response of the earth before climate change. This epistemic uncertainty can be reduced when more data become available. To account for this uncertainty, this analysis defines three possible climate change scenarios so-called: without, expected and pessimistic global warming. The characteristics of the selected scenarios gather the information currently available and make consistent assumptions when needed. A complete description of these considerations is given in (BastidasArteaga et al. 2010). The most important factors considered in such study are:

- carbon dioxide, methane and nitrous oxide emissions;

- global population growth;

- introduction of new and clean technologies leading to the reduction of the impact of global change; and

- use of fossil sources of energy.

Thus, each scenario is defined in terms of:

- the difference between the annual means of temperature for the initial year $T\left(t_{0}\right)$ and the year of the end of the forecast $T\left(t_{a}\right), \Delta T$,

- the difference between the annual mean of relative humidity for $h\left(t_{0}\right)$ and $h\left(t_{a}\right), \Delta h$, and 
- the difference between the normalized durations of cold seasons for $R\left(t_{0}\right)$ and $R\left(t_{a}\right), \Delta R$.

By taking as reference a period of analysis of 100 yearsi.e., $t_{a}=100 \mathrm{yr}$, Table 2 provides the features and the values of $\Delta T, \Delta h$ and $\Delta R$ for each scenario. It is important to mention that the values presented in Table 2 are not downscaled from global circulation models for a specific location but they roughly correspond to expected values for middle and equatorial latitudes for AR5 scenarios. They will be used in the numerical example (Sect. 5) for illustrative purposes.

Although in general terms the presented model simulates the effect of seasonal variations and climate on temperature and humidity, it is important to stress that predicted values only represent an overall behavior which does not include the randomness of the phenomena. The following section addresses this and other random aspects.

\section{Probabilistic Approach}

\subsection{Modeling Weather Uncertainties}

To improve the predictability of the assessments, it is important to implement a weather model that reproduces realistically the temperature and the humidity during the period of analysis. Within this context, stochastic process models were used to represent the random nature of the weather parameters. Taking into account the simplicity of the implementation and the computational time, KarhunenLoève expansion is appropriate to represent the weather variables. Let $\kappa(t, \theta)$ be a random process, which is function of time $t$ and defined over the domain $\mathbf{D}$ with $\theta$ belonging to the space of random events $\boldsymbol{\Omega} ; \kappa(t, \theta)$ can thus be expanded as follows (Ghanem and Spanos 1991):

$$
\kappa(t, \theta) \simeq \bar{\kappa}(t)+\sum_{i=1}^{n_{K L}} \sqrt{\lambda_{i}} \xi_{i}(\theta) f_{i}(t)
$$

where $\bar{\kappa}$ is the mean of the process (Eqs. 17 and 18$), \xi_{i}(\theta)$ is a set of normal random variables, $n_{K L}$ is the number of terms of the truncated discretization, $f_{i}(t)$ are a complete set of deterministic orthogonal functions and $\lambda_{i}$ are the eigenvalues of the covariance function $C\left(t_{1}, t_{2}\right)$ :

$$
C\left(t_{1}, t_{2}\right)=e^{-\left|t_{1}-t_{2}\right| / b}
$$

where $b$ is the correlation length, which must be expressed in the same units as $t$. Since closed-form solutions for $f_{i}(t)$ and $\lambda_{i}$ are obtained for an exponential covariance (Ghanem and Spanos 1991), this paper assumes that the processes of temperature and humidity follow this kind of covariance.

\subsection{Probability of Failure}

The integration of the deterioration model presented previously into a suitable probabilistic framework is necessary to perform efficient probabilistic lifetime assessments and reliability analysis. The cumulative distribution function $(\mathrm{CDF})$ of the total lifetime, $F_{t_{T}}(t)$, is:

$$
F_{t_{T}}(t)=\operatorname{Pr}\left\{t_{T} \leq t\right\}=\int_{t_{c p}+t_{p t}+t_{c g} \leq t} f(\underline{\mathbf{x}}) d \underline{\mathbf{x}}
$$

where $\underline{\mathbf{x}}$ is the vector of random variables to be taken into account and $f(\underline{\mathbf{x}})$ is the joint probability density function of $\underline{\mathbf{x}}$. Defining failure in terms of the crack size, the limit state function becomes:

$$
g(\underline{\mathbf{x}}, t)=a_{c}(\underline{\mathbf{x}})-a_{t}(\underline{\mathbf{x}}, t)
$$

where $a_{t}(\underline{\mathbf{x}}, t)$ is the crack or pit size at time $t$ and $a_{c}(\underline{\mathbf{x}})$ is the critical crack or pit size that generates structural failure. The terms $a_{c}(\underline{\mathbf{x}})$ and $a_{t}(\underline{\mathbf{x}}, t)$ also include the pit size because pit growth also induces structural failure when the pit growth rate is higher than the crack growth rate. In this work, $a_{c}(\underline{\mathbf{x}})$ is treated as a random variable resulting from the evaluation of other limit state of member resistance, $g_{r}(\bullet)$. For instance, for the limit state of bending, $g_{r}(\bullet)$ becomes:

$$
g_{r}\left(A_{s}, P, \underline{\mathbf{x}}\right)=M_{f}\left(A_{s}, \underline{\mathbf{x}}\right)-M_{e}(P, \underline{\mathbf{x}})
$$

where $A_{S}$ is the cross-sectional area of reinforcement, $P$ is the applied load, $\underline{\mathbf{x}}$ is the vector of random variables (i.e. concrete compressive strength, yield stress, etc.), $M_{f}\left(A_{s}, \underline{\mathbf{x}}\right)$ is the bending moment capacity and $M_{e}(P, \underline{\mathbf{x}})$ is the bending moment due to the load $P$. Failure is reached in Eq. (23)

\begin{tabular}{|c|c|c|c|}
\hline Scenario & $\Delta T\left({ }^{\circ} \mathrm{C}\right)$ & $\Delta h$ & $\Delta R$ \\
\hline Without climate change is neglected & 0 & 0 & 0 \\
\hline $\begin{array}{l}\text { Expected Use of alternative and fossil sources of energy, } \\
\text { birthrates follow the current patterns and there is no extensive } \\
\text { employ of clean technologies (equivalent to scenarios } \\
\text { RCP2.6-RCP4.5 depending on the location) }\end{array}$ & 2.5 & 0.05 & -0.1 \\
\hline $\begin{array}{l}\text { Pessimistic Vast utilization of fossil sources of energy, } \\
\text { appreciable growth of population and there are no policies to } \\
\text { develop and extend the use of clean technologies (equivalent } \\
\text { to scenarios RCP6-RCP8.5 depending on the location) }\end{array}$ & 6.5 & 0.1 & 0.2 \\
\hline
\end{tabular}
when $A_{s}$ is equal to a critical value $A_{s c}$. By taking into consideration that $A_{s c}$ can be expressed as a function of the critical crack or pit size, $a_{c}$ is computed by solving:

Table 2 Climate change scenarios. 


$$
M_{f}\left(A_{s c}\left(a_{c}\right), \underline{\mathbf{x}}\right)=M_{e}(P, \underline{\mathbf{x}})
$$

Note that, although $a_{c}(\underline{\mathbf{x}})$ does not depend on both the corrosion process and the frequency of the cyclic load, the time to reach $a_{c}(\underline{\mathbf{x}}), t_{T}$, depends on both environmental aggressiveness and the frequency of the cyclic load (Bastidas-Arteaga et al. 2009). For the limit state function expressed by Eq. (22) the failure probability, $p_{f}$, can be estimated as:

$$
p_{f}=\int_{g(\underline{\mathbf{x}}, t) \leq 0} f(\underline{\mathbf{x}}) d \underline{\mathbf{x}}
$$

Closed-form solutions for both the CDF of the total corrosion-fatigue lifetime and the failure probability are very difficult to obtain. Therefore, Monte Carlo simulations and Latin hypercube sampling are used herein to deal with this problem.

\section{Numerical Example}

\subsection{Problem Description}

The goal of this example is to evaluate the influence of realistic environmental conditions and cyclic loading on the reliability a simply supported RC bridge girder presented in Fig. 3. Table 3 describes the design load and material properties considered. It is assumed that the girder is built by using ordinary Portland cement. The bridge girder was designed according to the Eurocode 2 (European standard 2004). The climatic conditions for all cases considered in this example are defined by:

- two environments: oceanic and tropical (Table 4);

- two scenarios of global warming: without and pessimistic (Table 2); and

- three levels of aggressiveness: low, moderate and high (Table 5).

The time to corrosion initiation considers flow of chlorides in one dimension where the Langmuir isotherm is used to account for chloride binding. The constants of the isotherm are $\alpha_{L}=0.1185$ and $\beta_{L}=0.09$. The effect of temperature on the binding process is not considered in the study. For a concrete elaborated with ordinary Portland cement the adsorption isotherm (BSB model) only depends on the values of $w / c$ and $t_{e}$ reported in Table 3 (Bastidas-Arteaga et al. 2011). Since Eq. (6) does not account for the influence of environmental variations on the corrosion rate, this paper only considers the interaction between surrounding weather and the chloride ingress process.

Fatigue loading is modeled by a random wheel load at the center of the span with a frequency, $f$, ranging between 50 and 2000 cycles per day. The probabilistic models used to estimate the time to corrosion initiation and those corresponding to corrosion-fatigue propagation are presented in Table 6. It is assumed that all the random variables are independent.

\subsection{Results}

\subsubsection{Influence of Weather Model}

Figure 4 shows the effect of the weather model (constant, time-variant and stochastic) on failure probability. These curves, obtained for the oceanic environment, do not consider the effect of global warming and correspond to a high level of environmental aggressiveness-i.e., $C_{\text {env }}=2.95 \mathrm{~kg} / \mathrm{m}^{3}$ and $i_{\text {th }}=5 \mu \mathrm{A} / \mathrm{cm}^{2}$.

Three types of environmental inputs are included in the analysis. The stochastic one includes seasonal variations and randomness for weather inputs (temperature and humidity). For the time-variant one, a sinusoidal function is used to consider the seasonal variations of temperature and humidity. Finally, the constant case supposes that temperature and humidity are constant in time-i.e., $T=15^{\circ} \mathrm{C}$, and $h=0.7 . C_{\text {env }}$ and $i_{\text {th }}$ are considered as constant values for all the cases.

In general, failure probability depends on the type of input entries and load frequency (f). Constant and time-variant models underestimate failure probabilities. For instance, for a traffic frequency of 50 cycles per day, a constant level of failure probability (i.e., $p_{f}=0.5$ ) is reached at 58, 69 and 113 years for stochastic, time-variant and constant entries, respectively. Taking as a reference the stochastic case, this implies that the time-variant and constant cases overestimate the time to reach $p_{f}=0.5$ respectively of 11 and 55 years. A similar behavior is observed when traffic frequency is increased. Since the total fatigue lifetime is highly dependent
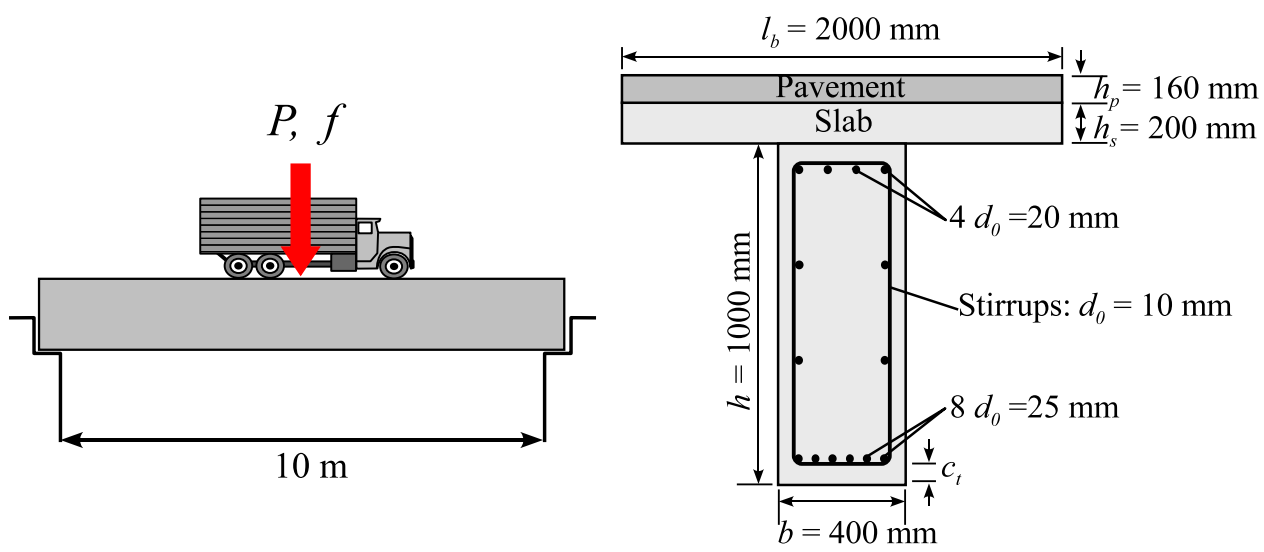

Fig. 3 Configuration of the bridge girder. 
Table 3 Design load and material constants.

\begin{tabular}{c|c}
\hline Variable & Value \\
\hline \hline Characteristic punctual design load, $P_{k}$ & $150 \mathrm{kN}$ \\
\hline Elastic modulus of steel, $E_{s t}$ & $200 \mathrm{GPa}$ \\
\hline Characteristic concrete compression strength, $f_{c k}^{\prime}$ & $30 \mathrm{MPa}$ \\
\hline Characteristic steel strength, $f_{y k}$ & $500 \mathrm{MPa}$ \\
\hline Concrete Poisson ratio, $v_{c}$ & 0.2 \\
\hline Water to cement ratio, $w / c$ & 0.5 \\
\hline Curing period, $t_{e}$ & 28 days
\end{tabular}

Table 4 Description of the studied environments.

\begin{tabular}{c|c|c|c|c|c|c}
\hline Climate & Latitude & $T_{\min }$ & $T_{\max }$ & $h_{\min }$ & $h_{\max }$ & $b^{\mathrm{a}}$ \\
\hline \hline Oceanic & Middle & $5{ }^{\circ} \mathrm{C}$ & $25^{\circ} \mathrm{C}$ & 0.6 & 0.8 & 0.1 year \\
\hline Tropical & Equatorial & $20^{\circ} \mathrm{C}$ & $30{ }^{\circ} \mathrm{C}$ & 0.7 & 0.9 & 0.1 year \\
\hline
\end{tabular}

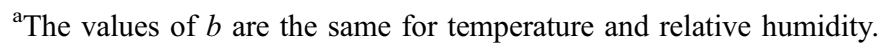

Table 5 Aggressiveness levels.

\begin{tabular}{c|c|c}
\hline Level & $C_{\text {env }}($ McGee 2000) & $i_{\text {th }}$ (Geocisa and the Torroja Institute 2002) \\
\hline \hline Low & $0.35 \mathrm{~kg} / \mathrm{m}^{3}$ & $0.5 \mu \mathrm{A} / \mathrm{cm}^{2}$ \\
\hline Moderate & $1.15 \mathrm{~kg} / \mathrm{m}^{3}$ & $2.0 \mu \mathrm{A} / \mathrm{cm}^{2}$ \\
\hline High & $2.95 \mathrm{~kg} / \mathrm{m}^{3}$ & $5.0 \mu \mathrm{A} / \mathrm{cm}^{2}$ \\
\hline
\end{tabular}

Table 6 Probabilistic models of the random variables (Bastidas-Arteaga et al. 2011).

\begin{tabular}{|c|c|c|c|c|}
\hline Variable & Units & Distribution & Mean & $\mathrm{COV}$ \\
\hline$D_{c, r e f}$ & $\mathrm{~m}^{2} / \mathrm{s}$ & Log-normal & $3 \times 10^{-11}$ & 0.20 \\
\hline$C_{t h}$ & wt $\%$ cem. & Normal $^{\mathrm{a}}$ & 0.5 & 0.20 \\
\hline$c_{t}$ & $\mathrm{~mm}$ & Normal $^{\mathrm{b}}$ & 50 & 0.25 \\
\hline$D_{h, r e f}$ & $\mathrm{~m}^{2} / \mathrm{s}$ & Log-normal & $3 \times 10^{-10}$ & 0.20 \\
\hline$\lambda$ & $\mathrm{W} /\left(\mathrm{m}^{\circ} \mathrm{C}\right)$ & Beta on $(1.4 ; 3.6)$ & 2.5 & 0.20 \\
\hline$c_{q}$ & $\mathrm{~J} /\left(\mathrm{kg}^{\circ} \mathrm{C}\right)$ & Beta on $(840 ; 1170)$ & 1000 & 0.10 \\
\hline$\rho_{c}$ & $\mathrm{~kg} / \mathrm{m}^{3}$ & Normal $^{\mathrm{a}}$ & 2400 & 0.05 \\
\hline$P$ & $\mathrm{kN}$ & Log-normal & 115 & 0.20 \\
\hline$f_{c}^{\prime}$ & $\mathrm{MPa}$ & Normal $^{\mathrm{a}}$ & 40 & 0.15 \\
\hline$f_{y}$ & $\mathrm{MPa}$ & Normal $^{\mathrm{a}}$ & 600 & 0.10 \\
\hline
\end{tabular}

\footnotetext{
${ }^{\mathrm{a}}$ Truncated at 0 .

${ }^{\mathrm{b}}$ Truncated at $10 \mathrm{~mm}$.
}

on time to corrosion initiation, it is expected that the type of input entries becomes a paramount parameter in the assessment of failure probability (Bastidas-Arteaga et al. 2011). These results justify the use of a more representative chloride ingress model including realistic environmental inputs for improving lifetime assessment with respect to the findings presented in (Bastidas-Arteaga et al. 2009).

\subsubsection{Failure Probabilities for Different Levels of Aggressiveness}

Figure 5 presents the failure probability of the beam for the tropical environment and the three considered levels of aggressiveness. The analysis included stochastic environmental entries and does not account for the action of climate change. 
(a)

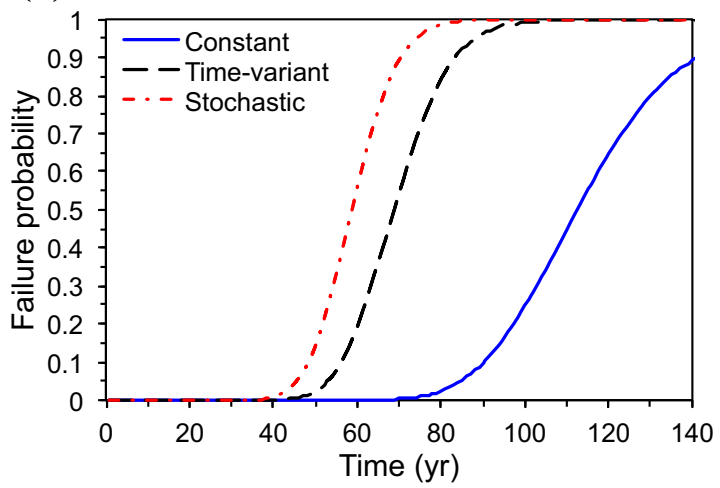

(b)

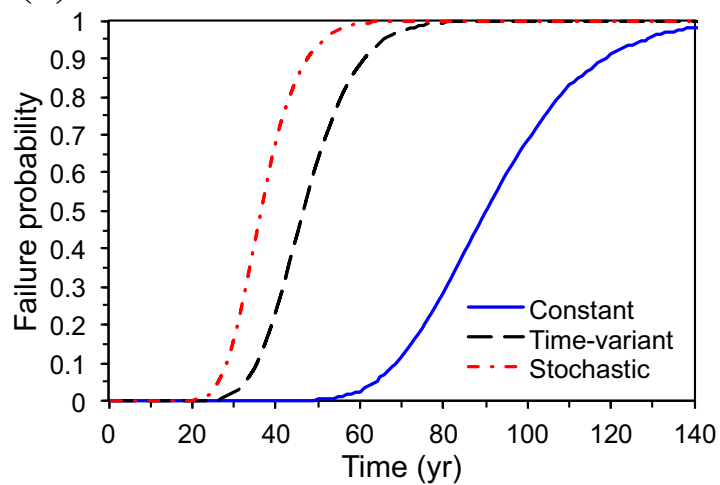

Fig. 4 Influence of the type of weather model on the failure probability for the oceanic environment and two traffic frequencies: a $f=50 /$ day, $\mathbf{b} f=2000 /$ day.

It is observed that the failure probability increases, in all cases, when the level of aggressiveness and the frequency tend to higher values. This increment is caused by: (i) higher concentrations of chlorides and corrosion rates of aggressive environments and (ii) quicker crack propagation under greater traffic frequencies. If the failure probabilities are evaluated for a life-cycle length of 50 years, it is noted that the structural reliabilities are very low for all levels of aggressiveness. By considering that the failure probability should be lower than a critical value to ensure a given safety level-i.e., $p_{f}<p_{f t}=10^{-4}$, the studied structural configuration only guarantees this condition for the moderate level when there is no cyclic load $\left(p_{f}=10^{-4}\right)$ and for the low level when there is no fatigue loading $\left(p_{f}=7 \times 10^{-5}\right)$ and traffic frequency is 50 cycles per day $\left(p_{f}=4 \times 10^{-4}\right)$. These results are not surprising because in real structures close to the sea, such as ports or quays, appreciable levels of deterioration have been reported after 15 or 20 years of (a)

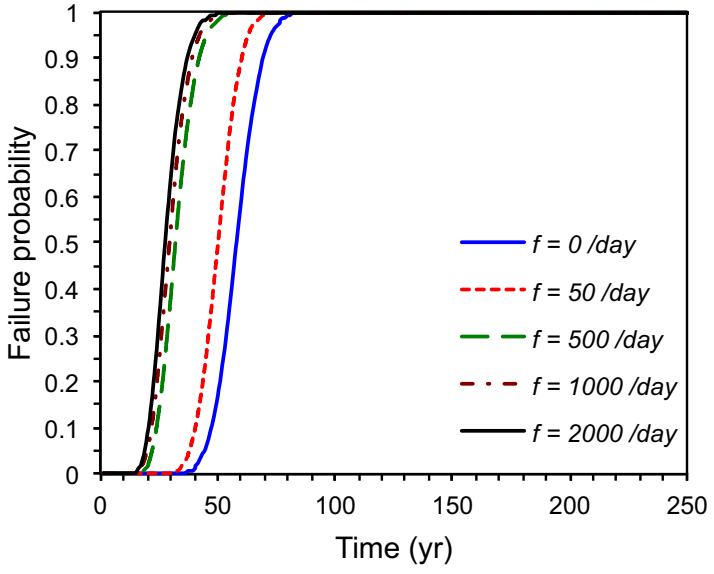

(b)

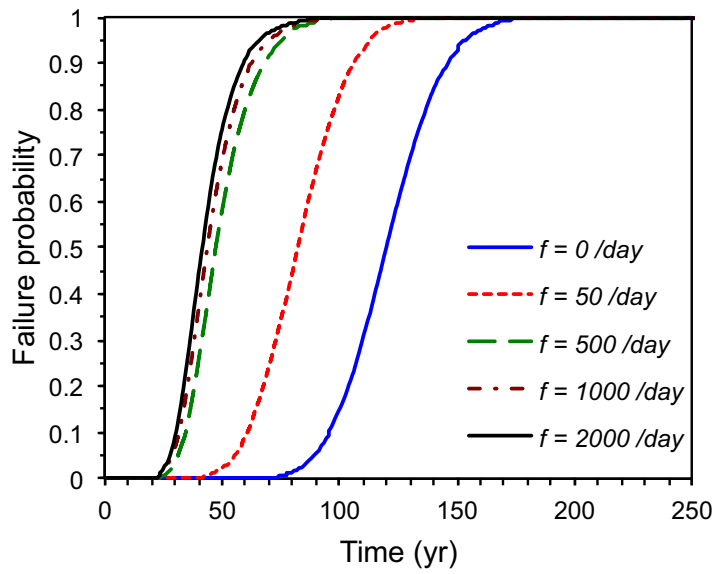

(c)

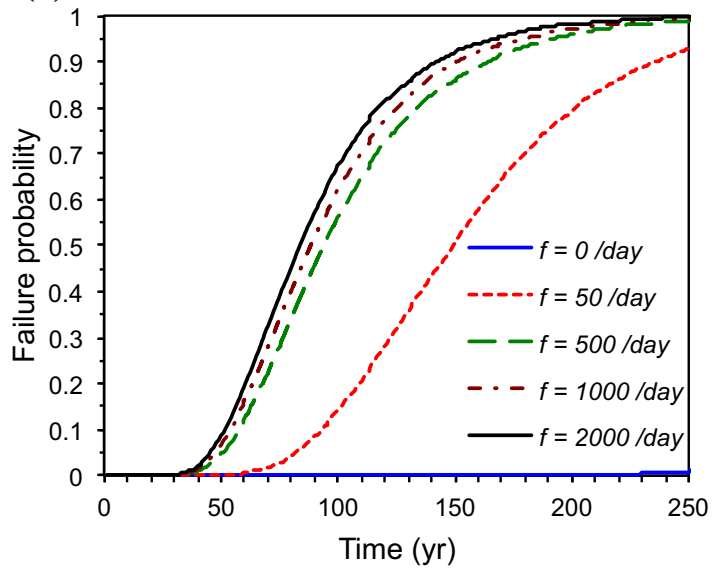

Fig. 5 Failure probabilities for the tropical environment under a high; $\mathbf{b}$ moderate and $\mathbf{c}$ low aggressiveness levels. 
exposure. The behavior for the oceanic environment is similar, but the failure probabilities are lower for all exposures and frequencies. This behavior indicates that a sophisticated model of chloride ingress calibrated with experimental observations and monitored with inspections should be included in the management of RC bridges to assure appropriate levels of safety during their lifecycle.

\subsubsection{Influence of Climate Change}

The effects climate change for the ocean and tropical climates on total lifetime are evaluated in terms of its probability density functions (PDFs). The PDFs for all the studied cases were adjusted from the Monte Carlo results where the selection criterion was the Kolmogorov-Smirnov test with a level of significance of 5\%. It was found for all cases that the best fitting corresponds to lognormal distributions. Tables 7 , 8 , and 9 present the mean and coefficient of variation (COV) of the total lifetime for two limit state functions. The results presented in Table 7 suppose that there is no cyclic loading, and consequently, the failure mechanism is corrosion-induced cross section reduction. In contrast, those showed in Tables 8 and 9 account for combined corrosion-fatigue deterioration damage.

When the girder is not subjected to cyclic loading or corrosion-fatigue damage is neglected, Table 7 shows that the mean and the COV of the total lifetime, $t_{T}$, decrease for more aggressive environments. It is observed in general that while the mean of $t_{T}$ is lower for tropical than for oceanic environments, the COV remains almost constant for both environments. This behavior seems logical because tropical environments are characterized by higher temperature and humidity that accelerate chloride ingress reducing corrosion initiation time. It is also noted that the effect of global warming is more important for structures located in oceanic environments. This analysis includes only the pessimistic scenario of global warming because there is no major difference between the expected and pessimistic scenarios. While for the tropical environment global warming only induced reductions from $0.4 \%$ to $0.7 \%$ in the mean of $t_{T}$, for the oceanic environment this reduction ranges between $1.4 \%$ and $2.3 \%$. It is concluded that climate change has more influence in environments where humidity and temperature are characterized by important seasonal variations.

The results of Tables 8 and 9 include the effect of corrosion-fatigue damage and climate change for tropical and oceanic environments, respectively. This analysis also includes the effect of traffic frequencies. Similar to the previous case, the mean and COV of $t_{T}$ decrease when the level of aggressiveness increases. By comparing both cases (with and without fatigue damage) it is observed that the mean of the PDF is reduced when the assessment considers the effect of the cyclic load. The reduction of the lifetime

Table 7 Mean (in years) and coefficient of variation (between brackets) of the total lifetime without fatigue effects.

\begin{tabular}{c|c|c|c|c}
\hline \multirow{2}{*}{$\begin{array}{c}\text { Environmental } \\
\text { aggressiveness }\end{array}$} & Without (\%) & Pessimist (\%) & Without (\%) & Pessimist (\%) \\
\cline { 2 - 5 } & $58.2(15)$ & $57.9(15)$ & $62.2(15)$ & $60.8(15)$ \\
\hline \hline High & $120.5(16)$ & $119.6(16)$ & $124.8(16)$ & $123(16)$ \\
\hline Moderate & $409.4(18)$ & $407.7(18)$ & $411.2(18)$ & $405.2(19)$ \\
\hline Low &
\end{tabular}

Table 8 Mean (in years) and coefficient of variation (between brackets) of the total lifetime for the tropical environment.

\begin{tabular}{c|c|c|c|c|c|c}
\hline \multirow{2}{*}{$\begin{array}{c}\text { Frequency } \\
\text { (cycles/day) }\end{array}$} & \multicolumn{2}{|c|}{ High aggressiveness } & \multicolumn{2}{c|}{ Moderate aggressiveness } & \multicolumn{2}{c}{ Low aggressiveness } \\
\cline { 2 - 7 } & Without (\%) & Pessimist (\%) & Without (\%) & Pessimist (\%) & Without (\%) & Pessimist (\%) \\
\hline \hline 50 & $50.2(15)$ & $49.8(15)$ & $82.9(21)$ & $81.8(21)$ & $157.7(36)$ & $153.8(35)$ \\
\hline 500 & $32.6(22)$ & $32.2(22)$ & $49.5(27)$ & $48.4(28)$ & $103.9(43)$ & $101.3(42)$ \\
\hline 1000 & $30(23)$ & $29.5(22)$ & $45.8(28)$ & $45.1(28)$ & $97.1(43)$ & $94.7(42)$ \\
\hline 2000 & $28.3(23)$ & $27.7(23)$ & $43.5(28)$ & $42.5(27)$ & $91.7(42)$ & $88.8(42)$ \\
\hline
\end{tabular}

Table 9 Mean (in years) and coefficient of variation (between brackets) of the total lifetime for the oceanic environment.

\begin{tabular}{c|c|c|c|c|c|c}
\hline \multirow{2}{*}{$\begin{array}{c}\text { Frequency } \\
\text { (cycles/day) }\end{array}$} & \multicolumn{2}{|c|}{ High aggressiveness } & \multicolumn{2}{c|}{ Moderate aggressiveness } & \multicolumn{2}{c}{ Low aggressiveness } \\
\cline { 2 - 7 } & Without (\%) & Pessimist (\%) & Without (\%) & Pessimist (\%) & Without (\%) & Pessimist (\%) \\
\hline \hline 50 & $54.1(16)$ & $52.7(15)$ & $86.9(21)$ & $85(21)$ & $159.3(35)$ & $153.1(36)$ \\
\hline 500 & $36.4(22)$ & $35.1(22)$ & $53.7(27)$ & $51.3(27)$ & $105.8(41)$ & $99.4(42)$ \\
\hline 1000 & $33.8(23)$ & $32.6(22)$ & $50.3(27)$ & $47.9(27)$ & $99.3(41)$ & $92.5(42)$ \\
\hline 2000 & $32.3(24)$ & $30.8(23)$ & $48.1(27)$ & $45.8(27)$ & $93.2(40)$ & $86.7(40)$ \\
\hline
\end{tabular}


induced by cyclic load can be estimated by setting the case without fatigue damage as the reference one. For example, for a case without climate change, oceanic environment, low aggressiveness, and $f=50$ cycles/day, the mean of $t_{T}$ is reduced by $61 \%$. For the same conditions but $f=2000$ cycles/day this value corresponds to $77 \%$. These results justify the consideration of combined damage mechanisms in lifetime assessment.

Similar to the case without fatigue damage, the structures located in oceanic environments are more susceptible to the effects of global warming. The reduction of the mean of $t_{T}$ varies between $0.8 \%$ and $2.5 \%$ for the tropical environment and ranges between $2.6 \%$ and $3.9 \%$ for the oceanic environment when traffic frequency is $f=50$ cycles/day. The impact of climate change increases for higher traffic frequency $(f=2000$ cycles/day) where reductions from $2.1 \%$ to $3.2 \%$ were observed for the tropical environment and from $4.4 \%$ to $7 \%$ for the oceanic environment. High traffic frequencies reduce the length of the stages of pit-to-crack transition and crack propagation (Eqs. 13 and 14), and consequently, the participation of the stage of time to corrosion initiation and pit nucleation becomes more important.

For all cases and environments, it is observed that the reduction induced by global warming is maximum $7 \%$ of total lifetime; however, it is important to clarify that these results are conservative because they do not include the effect of global warming after corrosion initiation. Nowadays, it is known that corrosion rate can be influenced by temperature and humidity, and therefore should be affected by climate change. Nevertheless, there is no a consensus about a comprehensive corrosion model that considers this interaction in a comprehensive manner. Further research in this area is required to improve the prediction after corrosion initiation.

\section{Conclusions}

This paper presented a deterioration model that integrates the effects of chloride-induced corrosion, climate change and cyclic loading for RC structures. The total corrosion-fatigue life was divided into three stages: (i) corrosion initiation and pit nucleation, (ii) corrosion initiation and pit nucleation, and (iii) crack growth. Since some of these stages are sensitive to climatic conditions, a simplified model of weather that includes global warming was also included. The whole deterioration model was introduced into a stochastic framework to take the inherent uncertainties into account. Finally, a numerical example illustrated the consequences of the deterioration process in the reliability of a $\mathrm{RC}$ bridge girder. It was found that for traffic frequencies between 500 and 2000 cycles/day, the combined effect of corrosion and fatigue leads to appreciable lifetime reductions. When no fatigue damage is considered, the climate change effect only induces lifetime reductions ranging between 1.4 and $2.3 \%$. Under cyclic loading, total lifetime could be reduced up to $7 \%$ by global warming action. These results highlight the importance of including the combined effect of corrosion and fatigue for comprehensive lifetime assessment.

\section{Open Access}

This article is distributed under the terms of the Creative Commons Attribution 4.0 International License (http:// creativecommons.org/licenses/by/4.0/), which permits un restricted use, distribution, and reproduction in any medium, provided you give appropriate credit to the original author(s) and the source, provide a link to the Creative Commons license, and indicate if changes were made.

\section{References}

Ahn, S. H., Lawrence, F. V., \& Metzger, M. M. (1992). Corrosion fatigue of an HSLA steel. Fatigue and Fracture of Engineering Materials and Structures, 15, 625-642.

Ahn, W., \& Reddy, D. V. (2001). Galvanostatic testing for the durability of marine concrete under fatigue loading. Cement and Concrete Research, 31, 343-349.

Akita, H., Fujiwara, T., \& Ozaka, Y. (1997). A practical procedure for the analysis of moisture transfer within concrete due to drying. Magazine of Concrete Research, 49(179), 129-137.

Al-Hammoud, R., Soudki, K., \& Topper, T. H. (2011). Fatigue flexural behavior of corroded reinforced concrete beams repaired with CFRP sheets. Journal of Composites for Construction, 15(1), 42-51. https://doi.org/10.1061/ (asce)cc.1943-5614.0000144.

Bastidas-Arteaga, E., Bressolette, P., Chateauneuf, A., \& Sánchez-Silva, M. (2009). Probabilistic lifetime assessment of RC structures under coupled corrosion-fatigue processes. Structural Safety, 31(1), 84-96. https://doi.org/10.1016/j. strusafe.2008.04.001.

Bastidas-Arteaga, E., Chateauneuf, A., Sánchez-Silva, M., Bressolette, P., \& Schoefs, F. (2010). Influence of weather and global warming in chloride ingress into concrete: A stochastic approach. Structural Safety, 32(4), 238-249. https://doi.org/10.1016/j.strusafe.2010.03.002.

Bastidas-Arteaga, E., Chateauneuf, A., Sánchez-Silva, M., Bressolette, P., \& Schoefs, F. (2011). A comprehensive probabilistic model of chloride ingress in unsaturated concrete. Engineering Structures, 33(3), 720-730. https:// doi.org/10.1016/j.engstruct.2010.11.008.

Bastidas-Arteaga, E., Sánchez-Silva, M., \& Chateauneuf, A. (2007). Structural reliability of RC structures subject to biodeterioration, corrosion and concrete cracking. In J. Kanda, T. Takada, \& H. Furuta (Eds.), 10th International Conference on Applications of Statistics and Probability in Civil Engineering (pp. 183-190). Tokyo.

Bastidas-Arteaga, E., \& Schoefs, F. (2015). Sustainable maintenance and repair of RC coastal structures. Proceedings of the Institution of Civil Engineers-Maritime Engineering, 168(4), 162-173. https://doi.org/10.1680/jmaen.14.00018. 
Bastidas-Arteaga, E., \& Stewart, M. G. (2016). Economic assessment of climate adaptation strategies for existing RC structures subjected to chloride-induced corrosion. Structure and Infrastructure Engineering, 12(4), 432-449. https://doi.org/10.1080/15732479.2015.1020499.

Bhide, S. (1999). Material Usage and Condition of Existing Bridges in the \{U.S.\}. Skokie, Ill.

Brunauer, S., Skalny, J., \& Bodor, E. (1969). Adsorption in nonporous solids. Journal of Colloid Interface Science, 30, 546-552.

Chen, G. S., \& Duquette, D. J. (1992). Corrosion fatigue of a precipitation-hardened Al-Li-Zr alloy in a $0.5 \mathrm{M}$ sodium chloride solution. Metallurgical Transactions, 23, 1563-1572.

Chen, G. S., Wan, K. C., Gao, M., Wei, R. P., \& Flournoy, T. H. (1996). Transition from pitting to fatigue crack growth modeling of corrosion fatigue crack nucleation in a 2024-T3. aluminum alloy. Materials Science and Engineering $A$, 219, 126-132.

Clifton, J. R. (1993). Predicting the service life of concrete. $A C I$ Materials Journal, 90, 611-617.

ElSafty, A., Graeff, M. K., \& Fallaha, S. (2014). Behavior of laterally damaged prestressed concrete bridge girders repaired with CFRP laminates under static and fatigue loading. International Journal of Concrete Structures and Materials, 8(1), 43-59. https://doi.org/10.1007/s40069013-0053-0.

European standard. (2004). Eurocode 1 and 2: Basis of design and actions on structures and design of concrete structures (AFNOR.).

Gangloff, R. P. (2005). Environmental cracking corrosion fatigue. In R. Baboian (Ed.), Corrosion tests and standards: Application and interpretation (pp. 302-321). West Conshohocken: ASTM International.

Geocisa, \& the Torroja Institute. (2002). Contecvet: A validated users manual for assessing the residual service life of concrete structures. Manual for assessing corrosion-affected concrete structures. Annex $C$ Calculation of a representative corrosion rate. British Cement Association, UK.

Ghanem, R. G., \& Spanos, P. D. (1991). Stochastic Finite Elements: A Spectral Approach. New York: Springer. $\mathrm{http}: / /$ link.springer.com/content/pdf/10.1007/978-1-46123094-6.pdf.

Imam, A., Anifowose, F., \& Azad, A. K. (2015). Residual strength of corroded reinforced concrete beams using an adaptive model based on ANN. International Journal of Concrete Structures and Materials, 9(2), 159-172. https:// doi.org/10.1007/s40069-015-0097-4.

Inman, M. (2011). Opening the future. Nature Climate Change, 1(1), 7-9. https://doi.org/10.1038/nclimate1058.

IPCC. (2013). T. F. Stocker, D. Qin, G.-K. Plattner, M. Tignor, S. K. Allen, J. Boschung, et al. (eds.), Climate Change 2013: The Physical Science Basis. Contribution of Working Group I to the Fifth Assessment Report of the Intergovernmental Panel on Climate Change. Cambridge, United Kingdom and New York, NY, USA: Cambridge University Press.
Jones, D. A. (1992). Principles and prevention of corrosion. New York: Macmillan Publishing Co.

Khan, A., Cook, W., \& Mitchell, D. (1998). Thermal properties and transient thermal analysis of structural members during hydration. ACI Materials Journal, 95(3), 293-303.

Kim, H.-R., Choi, W.-C., Yoon, S.-C., \& Noguchi, T. (2016). Evaluation of bond properties of reinforced concrete with corroded reinforcement by uniaxial tension testing. International Journal of Concrete Structures and Materials, 10(S3), 43-52. https://doi.org/10.1007/s40069-016-0152-9.

Koch, G., Varney, J., Thompson, N., Moghissi, O., Gould, M., \& Payer, J. (2016). International measures of prevention, application, and economics of corrosion technologies study (p. 77084). Houston, TX: NACE International IMPACT Report.

Kondo, Y. (1989). Prediction of fatigue crack initiation life based on pit growth. Corrosion, 45, 7-11.

Marquez-Peñaranda, J. F., Sanchez-Silva, M., Husserl, J., \& Bastidas-Arteaga, E. (2016). Effects of biodeterioration on the mechanical properties of concrete. Materials and Structures, 49(10), 4085-4099. https://doi.org/10.1617/ s11527-015-0774-4.

Masoud, S., Soudki, K., \& Topper, T. (2005). Postrepair fatigue performance of FRP-repaired corroded RC beams: Experimental and analytical investigation. Journal of Composites for Construction, 9(5), 441-449. https://doi.org/10.1061/ (asce)1090-0268(2005)9:5(441).

McGee, R. (2000). Modelling of durability performance of Tasmanian bridges. In R. E. Melchers \& M. G. Stewart (Eds.), Applications of statistics and probability in civil engineering (pp. 297-306). Rotterdam: Balkema.

Morga, M., \& Marano, G. C. (2015). Chloride penetration in circular concrete columns. International Journal of Concrete Structures and Materials, 9(2), 173-183. https://doi. org/10.1007/s40069-014-0095-y.

Mori, Y., \& Ellingwood, B. R. (1995). Reliability-based life prediction of structures degrading due to environment and repeated loading. In M. Lemaire, J. L. Favre, \& A. Mébarki (Eds.), Applications of statistics and probability: Civil engineering reliability and risk analysis (pp. 971-976). Paris: Balkema.

Moss, R. H. R. H., Edmonds, J. A. J. A., Hibbard, K. A. K. A., Manning, M. R., Rose, S. K. S. K., van Vuuren, D. P. D. P., et al. (2010). The next generation of scenarios for climate change research and assessment. Nature, 463(7282), 747-756. https://doi.org/10.1038/nature08823.

Murakami, Y., \& Nisitani, H. (1975). Stress intensity factor for circumferentially cracked round bar in tension. Transactions of the Japan Society of Mechanical Engineers, 41, 360-369.

Nguyen, P.-T., Bastidas-Arteaga, E., Amiri, O., \& El Soueidy, C.-P. (2017). An efficient chloride ingress model for longterm lifetime assessment of reinforced concrete structures under realistic climate and exposure conditions. International Journal of Concrete Structures and Materials, 11(2), 199-213. https://doi.org/10.1007/s40069-017-0185-8.

Pritzl, M. D., Tabatabai, H., \& Ghorbanpoor, A. (2014). Laboratory evaluation of select methods of corrosion 
prevention in reinforced concrete bridges. International Journal of Concrete Structures and Materials, 8(3), 201-212. https://doi.org/10.1007/s40069-014-0074-3.

Radlińska, A., McCarthy, L. M., Matzke, J., \& Nagel, F. (2014). Synthesis of DOT use of beam end protection for extending the life of bridges. International Journal of Concrete Structures and Materials, 8(3), 185-199. https://doi.org/10. 1007/s40069-014-0077-0.

Rajasankar, J., \& Iyer, N. R. (2006). A probability-based model for growth of corrosion pits in aluminum alloys. Engineering Fracture Mechanics, 73, 553-570.

Saetta, A., Scotta, R., \& Vitaliani, R. (1993). Analysis of chloride diffusion into partially saturated concrete. $A C I$ Materials Journal, 90(5), 441-451.

Salah el Din, A., \& Lovegrove, J. M. (1982). Fatigue of cold worked ribbed reinforcing bar-A fracture mechanics approach. International Journal of Fatigue, 4, 15-26.

Sánchez-Silva, M., \& Klutke, G.-A. (2016). Reliability and lifecycle analysis of deteriorating systems. Cham: Springer International Publishing. https://doi.org/10.1007/978-3319-20946-3.
Song, L., \& Yu, Z. (2015). Fatigue flexural behaviour of corroded RC beams strengthened with CFRP sheets. IJEMS Vol. 22(1) [February 2015].

Stewart, M. G., Wang, X., \& Nguyen, M. N. (2011). Climate change impact and risks of concrete infrastructure deterioration. Engineering Structures, 33(4), 1326-1337. https:// doi.org/10.1016/j.engstruct.2011.01.010.

Vu, K. A. T., \& Stewart, M. G. (2000). Structural reliability of concrete bridges including improved chloride-induced corrosion. Structural Safety, 22, 313-333.

Wang, X. H., Bastidas-Arteaga, E., \& Gao, Y. (2018). Probabilistic analysis of chloride penetration in reinforced concrete subjected to pre-exposure static and fatigue loading and wetting-drying cycles. Engineering Failure Analysis, 84, 205-219. https://doi.org/10.1016/j.engfailanal.2017.11. 008

Xi, Y., Bažant, Z., \& Jennings, H. (1994). Moisture diffusion in cementitious materials-Adsorption isotherms. Advanced Cement Based Materials, 1(6), 248-257. 